\title{
The Correctness Problems in Applying Inductive Statistics in Economics and Agriculture
}

\author{
*Andrejs Jaunzems, Ilze Balode \\ Ventspils University College, Inženieru Street 101, Ventspils, LV-3600, Latvia
}

\begin{abstract}
In the article "Professor Tinbergen's Method" (Keynes J. M. Professor Tinbergen's Method. The Economic Journal. 1939. Vol. 49. No. 195) John Maynard Keynes expressed critical notes concerning insufficient scientific level of the Jan Tinbergen's results obtained with the help of econometric methods. The conclusion of present research is that the critical appraisal of econometric applying given by John Maynard Keynes in 1939 can be completely assigned to many published in Latvia research in economics and business done by inductive statistics because scientists carelessly apply the linear regression model in absence of the knowledge a priori required by proper theorems and algorithms. Moreover, many times there is no sense even to speak about stochastic experiment because the most important condition - ceteris paribus does not fulfil, namely, economic environment is not homogeneous enough. As the result, the causal inferences derived from Regression Report are not scientifically justified. The second conclusion is that the objective criticism in econometrics applications area in order to keep the satisfactory level of scientific correctness and scientific ethics in Latvia has to be established. We also assert that the applications of inductive econometrics in agriculture are much more justified due to possibility to repeat the stochastic experiments many times in constant circumstances like in physics and mechanics. The meta-target of present article is to remind the protests of John Maynard Keynes to the careless utilization of econometric theorems and to raise a wide discussion about the problems of correctness in applying inductive statistics in economics and agriculture in Latvia.
\end{abstract}

Key words: randomness, probability, descriptive statistics, inductive statistics, linear regression.

\section{Introduction}

David Friedman asserts (Friedman, 2005): “Causal inference from observational data presents many difficulties, especially when underlying mechanisms are poorly understood."

Getting acquainted with a big number of scientific publications, we have to agree with such severe judgement. Really, our didactic and scientific experience over a long time period confirms that also in Latvia economists, managers and especially administrators "poorly understand" the essence of the inductive statistics basic concepts and theorems.

Documented experimental testing, carried out by the authors, clearly signals that methodology of inductive statistics is often not strictly separated from methodology of descriptive statistics. The difficulties for users cause even the basic concepts, for example, the mathematical n-sample from general set and its functions (statistics).

No doubt that the deepest reason is the insufficient general mathematical education that is continuously and widely discussed in Latvia. The following seems for us self-evident: if during studies of mathematics one does not understand, for instance, the concept of real sequence limit (say, equality $\lim _{n \rightarrow \infty} \frac{1}{n}=0$ ), then it goes without saying that this person later will not be able to understand the concept of limit by probability of random number sequence (for instance, the Bernoulli law of big numbers $\lim _{\mathrm{n} \rightarrow \infty} \mathrm{W}_{\mathrm{n}}=\zeta$ ).

The studies of scientific papers published in Latvia show that very popular tool for quantitative research of economical and agricultural processes in Latvia is the model of linear regression. As an illustration for

\footnotetext{
* Corresponding Author's email: jaunzems@venta.1v
} 
the problem discussed in this paper, we could take any publication containing linear regression. In order not to look far away, we appeal to the readers to take our discussion about the linear regression models displayed in current Scientific Journal as an example.

It is easy to understand the interest and the willingness of the authors in application of econometric models. The first reason is that it is very easy to provide the practical calculus with the help of computers and proper software. The second reason is that Regression Report passed by computer looks very scientific and attaches the scientific gloriole to the research. The third reason is that sometimes the authors really believe that the numbers in Regression Report can be scientifically interpreted for causal inference purposes.

The problems arise because the calculations and interpretations of indicators in Regression Report (regressions, confidence intervals, t-statistics, p-values, etc.) are based on the theorems of inductive statistics, proofs of which are based on strong assumptions. Therefore, the correct applications of these indicators for causal inference in economic or agricultural investigations require a priori knowledge and fulfilment of proper conditions. However, we must point out that scientists in Latvia as a rule openly ignore that applications of linear regression model endangers serious correctness problems. To characterize the situation in Latvia, it seems suitable to employ the rough expression of foreign scientist Lars Pålsson Syll (Sull, 2013): "Nowadays, serious arguments have been made from data. Beautiful, delicate theorems have been proved although the connection with data analysis often remains to be established. And an enormous amount of fiction has been produced, masquerading as rigorous science." A. Jaunzems has already discussed this problem in the paper (Jaunzems, 2015).

In present paper, our aim is not to criticize concrete scientific articles in the above mentioned context of "scientific fiction masquerading as rigorous science". But we are sure that objective well-wishing scientific criticism in econometrics applications area has to be established in order to keep the satisfactory level of scientific correctness. It would be welcomed to find consensus among scientists to take critical notes in account only as scientific non-private polemics.

To create platform for further discussions on problem denoted by Lars Pålsson Syll as "scientific fiction masquerading as rigorous science" in this paper our target is to formulate the problem and expose most widespread mistakes and misunderstandings. In order to be as precise as possible and as understandable as possible, we offer to start the discussion with the simplest case - the linear regression model.

\section{Materials and Methods}

In the theoretical sense, our research is based on philosophy, mathematics and econometrics. The investigation of causal inference in inductive statistics is impossible without organic utilization of the categories of dialectics: "particular and general", "reasons and consequences", "contingency and necessity", "deduction and induction". Of course, substantial understanding of mathematics and econometric theory foundations is absolutely necessary.

The empirical material for our research consists of two parts. The first part is connected with our significant didactic experience and has been acquired by the observations of teaching-learning results in statistics and econometrics. The second part has been acquired by analysis of the scientific publications concerning inductive statistics.

We are interested in two types of scientific publications.

The first type is those scientific publications, which contain applying of linear regression. These publications are the object for its theoretical level and correctness scientific criticism. Let us do not mention the concrete authors and concrete papers yet in this paper. We would like to leave it for future because we hope the consensus will be reached and the scientific criticism of econometric investigations will be legitimized.

The second type is the scientific publications, which contain the criticism of an incorrect applications.

Econometrics is applied for causal inference. Unfortunately, these are publications only by foreign scientists. We have examined a big number of such kind of papers; the reader can get particular information, for instance, from references in the David A. Freedman article (Freedman, 2005) containing 91 titles.

The historical studies allow us to assert that the problem of correctness in applying inductive statistics in economics and agriculture is recognized as a very important problem of scientific ethics. The ignorance of necessary a priori knowledge in applying of inductive statistic theorems has a long history.

We found support to our assertions in the discussion of John Maynard Keynes ${ }^{1}$ with Jan Tinbergen $^{2}$ in 1939. John Maynard Keynes expressed critical notes concerning insufficient scientific level

\footnotetext{
John Maynard Keynes, 1883-1946.

Jan Tinbergen, 1903-1994.
} 
of the Jan Tinbergen's results obtained with help of econometric methods about the factors influenced volume of investments.

Discussion is displayed in the following wellknown publications (Keynes, 1939; Tinbergen, 1940; Keynes, 1940):

Keynes J. M. Professor Tinbergen's Method. The Economic Journal. 1939. Vol. 49. No. 195,

Tinbergen J. On a Method of Statistical BusinessCycle Research: A Reply. - The Economic Journal. 1940. Vol. 50. No. 197,

Keynes J. M. Comment. - The Economic Journal. 1940. Vol. 50. No. 197.

For readers in Latvia these publications became easily available thanks to the book (Кейнс, 2007): Кейнс Джон Мейнард. Общая теория занятости, процента и денег. Избранное. - Москва: Эксмо, 2007. -960 c.

We would like to stress the special role of the papers of David A. Freedman (Friedman, 2005), Lars Pålsson Syll (Syll, 2012; Syll, 2013) and Kevin D. Hoover (Hoover, 2005) as source that emits inspiration.

We regard as honour to remind to Latvian scientists the opinion of John Maynard Keynes in the announced problem.

\section{Results and Discussion}

In order to structure the results and discussion, they are stated in five short chapters.

In the first chapter with the help of an example, we examine the construction of model of linear regression and logical mistakes committed in econometric researches in Latvia.

In the second chapter, the critical notes expressed by John Maynard Keynes concerning insufficient scientific level of the Jan Tinbergen's results obtained with the help of econometric methods are considered.

In the third chapter, we shortly mention some other papers about wrong applications of inductive statistics as a tool to make rigorous science illusions.

In the fourth chapter as an example of extremely wrong application, we offer the so-called model of Altman (the Z-score formula). As an example of sufficiently more successful application of linear regression model, we consider some models of agriculture.
The fifth chapter contains the answers of scientists to excuse the insufficient scientific level of methods.

1. The linear regression model premises.

1.1. The linear regression model premises in the descriptive statistics.

The practical application of the linear regression in descriptive statistics does not create logical problems. The role of premise for deductive conclusions plays experimentally observed numbers. The enigmatic term "probability" in the descriptive statistics does not appear.

Example 1. Researcher has 10 times measured values of variable $y$ as regressand that corresponds to the different selected values of variable $\mathrm{x}$ as regressor. The results of pair $(\mathrm{x}, \mathrm{y})$ measurement are shown in the Table 1.

In Figure 1 the researcher depicts the results of 10 observations as points in Oxy plane and calculates equation of straight line $\mathrm{y}=2.31 \mathrm{x}-4.06$ as the best approach of the depicted 10 points according the least square method.

Everything is absolutely correct. The only premises for deductive conclusions are the observed pairs of numbers $(\mathrm{x}, \mathrm{y})$. The problems could arise for the quality of measurement or concerning the interpretations of equation $\mathrm{y}=2.31 \mathrm{x}-4.06$ graphically depicted in Figure 1.

If the researcher is interested to approach observed 10 points with parabola, he regresses linear y against $\mathrm{x}$ and $\mathrm{x}^{2}$, and gets quadratic function $\mathrm{y}=0.51 \mathrm{x}^{2}-$ $1.19 \mathrm{x}+1.47$ graphically depicted in Figure 2.

It is up to researcher which form of linear or nonlinear function for approximation of these empirical 10 points to choose.

1.2. The premises for the unknown straight line recovering (algebraic method).

Example 2. Let us assume that we know a priori that between $\mathrm{x}$ and $\mathrm{y}$ relation $\mathrm{y}=\beta_{1} \cdot \mathrm{x}+\beta_{0}$, where $\beta_{1}, \beta_{0} \in \mathbf{R}$, holds. It is given for us that we are able to repeat the statistic experiment - the empirical observation of pairs $(\mathrm{x}, \mathrm{y})$ as many times as we want to. It means that we can choose freely the values of variable $\mathrm{x}$ as regressor and to measure corresponding values of variable y as regressand. Are we capable to find unknown coefficients $\beta_{1}, \beta_{0}$ ?

Let us assume, for example, that between variables $\mathrm{x}, \mathrm{y}$ the linear relation $\mathrm{y}=2 \mathrm{x}-3$ holds, but we do

Table 1

Empirically observed 10 pair of numbers $(x, y)$

\begin{tabular}{|l|c|c|c|c|c|c|c|c|c|c|}
\hline $\mathrm{x}$ & 2 & 3 & 4 & 2 & 4 & 5 & 3 & 5 & 4 & 4 \\
\hline $\mathrm{y}$ & 0.70 & 1.72 & 5.24 & 2.28 & 6.20 & 8.73 & 0.82 & 6.77 & 6.10 & 3.91 \\
\hline
\end{tabular}




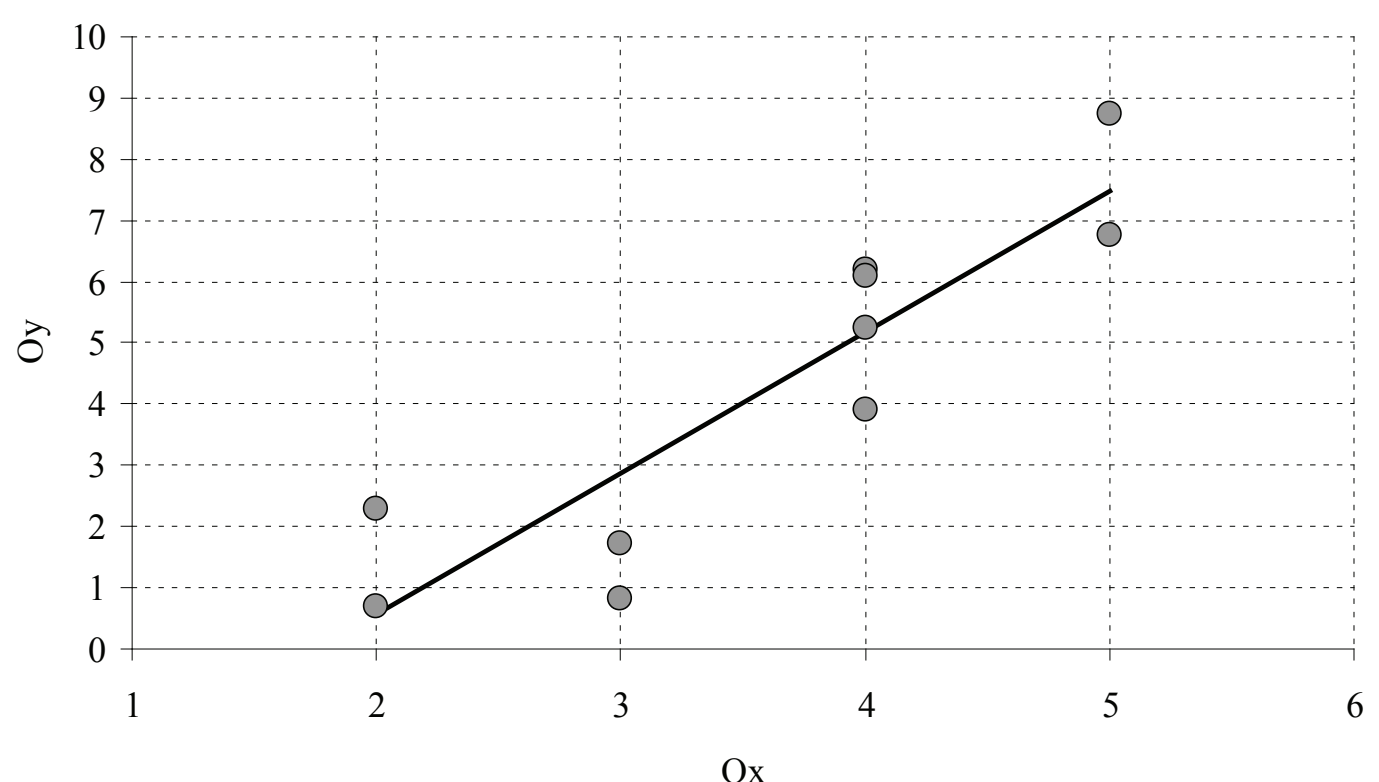

Figure 1. The observed 10 points and their approximation with straight-line $\mathrm{y}=2.31 \mathrm{x}-4.06$ calculated with the least square method.

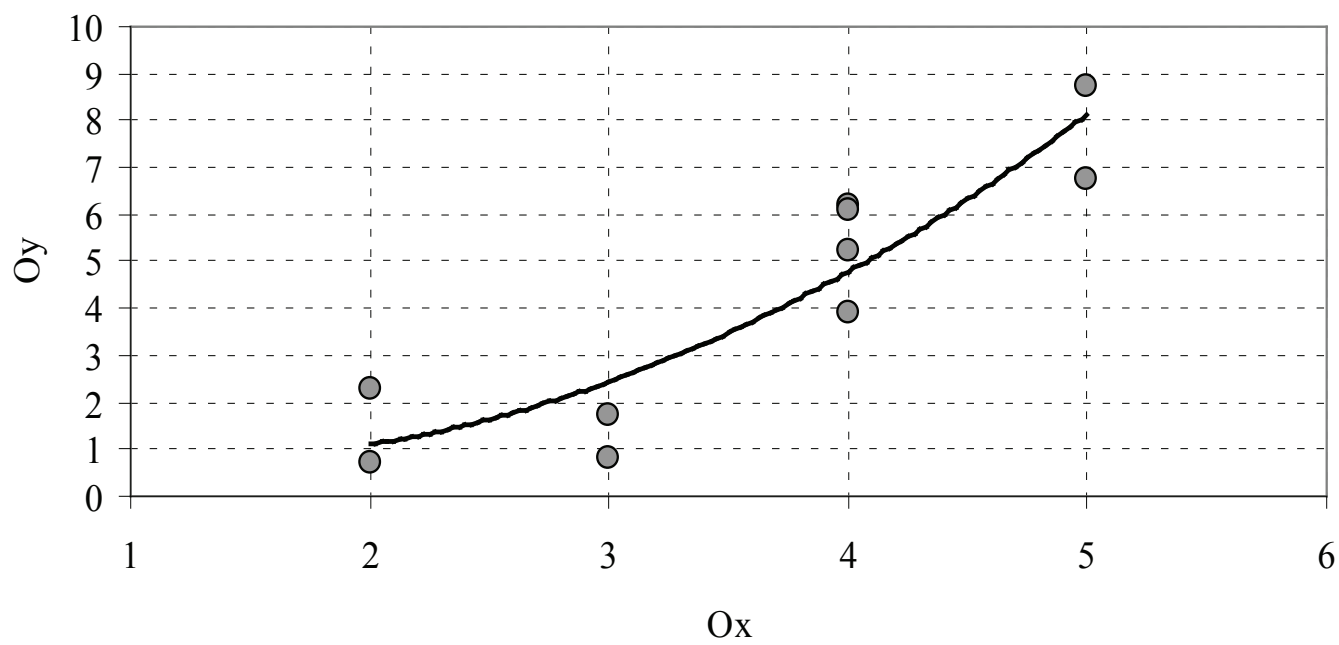

Figure 2. The observed 10 points and their approximation with parabola $y=0.51 x^{2}-1.19 x+1.47$ calculated with the least square method.

not know the coefficients 2 and -3 . How to find these unknown coefficients?

Let us take $\mathrm{x}=2$ and observe $\mathrm{y}=1$. Then we take $\mathrm{x}=3$ and measure $\mathrm{y}=3$.

We have two equations: $\beta_{1} \cdot 2+\beta_{0}=1 ; \beta_{1} \cdot 3+$ $\beta_{0}=3$.

Solving the system, we find $\beta_{1}=2, \beta_{0}=-3$.

The linear equation is discovered: $y=2 x-3$.

Let us stress our assumption. The fact that the two observations allow us to calculate coefficients does not mean that we proved the existence of linear equation $\mathrm{y}=2 \mathrm{x}-3$. Directly opposite, the a priori knowledge about existence of linear dependence $y=\beta_{1} \cdot x+\beta_{0}$ allows us to interpret the results of observations and calculations.

The general problem about linear algebraic restoring the unknown dependence between variables $\mathrm{x}_{1}, \mathrm{x}_{2}, \ldots, \mathrm{x}_{\mathrm{s}}$ as regressors and variable $\mathrm{y}$ as regressand can be formulated as follows.

We a priori know that the variable $\mathrm{y}$ is the linear combination of given $m$ functions $f_{1}, f_{2}, \ldots, f_{m}$ of independent $\mathrm{s}$ variables $\mathrm{x}_{1}, \mathrm{x}_{2}, \ldots, \mathrm{x}_{\mathrm{s}}$ :

$$
y=\beta_{1} \cdot f_{1}\left(x_{1}, x_{2}, \ldots, x_{s}\right)+\beta_{2} \cdot f_{2}\left(x_{1}, x_{2}, \ldots, x_{s}\right)+\ldots
$$
$+\beta_{\mathrm{m}} \cdot \mathrm{f}_{\mathrm{m}}\left(\mathrm{x}_{1}, \mathrm{x}_{2}, \ldots, \mathrm{x}_{\mathrm{s}}\right)$.

The coefficients $\beta_{1} \beta_{2} \ldots \beta_{\mathrm{m}}$ are unknown. How can we discover them? 
After $\mathrm{m}$ empirical observations we have the values $y_{i}$, that correspond to the values of independent variables $\left(\mathrm{x}_{\mathrm{i} 1}, \mathrm{x}_{\mathrm{i} 2}, \ldots, \mathrm{x}_{\mathrm{is}}\right), \mathrm{i} \in\{1,2, \ldots, \mu\}$.

Solving linear system

$\mathrm{y}_{\mathrm{i}}=\beta_{1} \cdot \mathrm{f}_{1}\left(\mathrm{x}_{1}, \mathrm{x}_{2}, \ldots, \mathrm{x}_{\mathrm{s}}\right)+\beta_{2} \cdot \mathrm{f}_{2}\left(\mathrm{x}_{1}, \mathrm{x}_{2}, \ldots, \mathrm{x}_{\mathrm{s}}\right)+\ldots$ $+\beta_{\mathrm{m}} \cdot \mathrm{f}_{\mathrm{m}}\left(\mathrm{x}_{1}, \mathrm{x}_{2}, \ldots, \mathrm{x}_{\mathrm{s}}\right)$,

$i \in\{1,2, \ldots, m\}$,

we obtain the values of unknown coefficients $\beta_{1}$ $\beta_{2} \ldots \beta_{\mathrm{m}}$.

The only condition is the non-singularity of matrix of equations system (see, for example (Jaunzems, 2003a)).

1.3. The premises of linear regression model in the inductive statistics.

Similar as before we know a priori that between $\mathrm{x}$ and $\mathrm{y}$ relation $\mathrm{y}=\beta_{1} \cdot \mathrm{x}+\beta_{0}$, where $\beta_{1}, \beta_{0} \in \mathbf{R}$, holds. It is allowed for us to choose freely the value of regressor $\mathrm{x}$ and to measure the corresponding value of regressand y as many times as we want to.

However, in the present case the measured value of $y$ has been spoiled by stochastic error $\mathrm{U}$.

It is known a priori that the error $\mathrm{U}$ is normally distributed with zero mean and unknown standard deviation $\sigma$. Moreover, we know a priori that during $\mathrm{m}$-sequence of statistic observation of regressand $\mathrm{y}$ the stochastic error $\mathrm{U}$ displays as iid (independent, identically distributed) $\mathrm{m}$-sequence $\left(\mathrm{U}_{1}, \mathrm{U}_{2}, \ldots, \mathrm{U}_{\mathrm{m}}\right)$ (Jaunzems, 2003b; 95).

Assumptions.

(1) We a priori know that $\mathrm{y}=\beta_{1} \cdot \mathrm{x}+\beta_{0}$, but we do not know coefficients $\beta_{1}, \beta_{0}$.

(2) We a priori know that by empirical measuring of regressand y its value is spoiled by normally distributed stochastic error $U$ with zero mean and unknown standard deviation $\sigma$.
(3) Moreover, we know that the stochastic error $\mathrm{U}$ during $\mathrm{m}$ measuring processes displays as iid m-sequence $\left(\mathrm{U}_{1}, \mathrm{U}_{2}, \ldots, \mathrm{U}_{\mathrm{m}}\right)$.

Therefore, the observed variable that corresponds to the chosen value of regressor $\mathrm{x}$ is random variable $\mathrm{Y}=\beta_{1} \cdot \mathrm{x}+\beta_{0}+\mathrm{U}$, where $\mathrm{U} \sim \mathrm{N}(0, \sigma)$; the sequence $\left(\mathrm{U}_{1}, \mathrm{U}_{2}, \ldots, \mathrm{U}_{\mathrm{m}}\right)$ is iid sequence.

After choosing the concrete value of regressor $\mathrm{x}$ and observing the proper value of regressand $\mathrm{y}$, we get empirical (observed) value $\beta_{1} \cdot \mathrm{x}+\beta_{0}+\mathrm{u}$ of random variable $\beta_{1} \cdot \mathrm{x}+\beta_{0}+\mathrm{U}$.

Example 3. We must recover unknown coefficients and unknown standard deviation. As before (example 2 ) we are going to restore linear equation $y=2 x-3$. In this case, we also have to find unknown standard deviation $\sigma$. (Let us assume that in fact $\sigma=1$.).

We are encountering the difficult task. The task is unsolvable!

That is the reason to admire the scientific results of inductive statistics provided for us with exact knowledge about properties of this unsolvable task solution.

Let us simulate our aspirations to find the unknown coefficients $\beta_{1}, \beta_{0}$ and unknown standard deviation $\sigma$ with the help of 10 empirical observations and with the help of proper inductive statistics theorem.

In Table 2 the true but unknown values of regressand $\mathrm{y}$ that correspond to the chosen values of regressor $\mathrm{x}$ are shown $(\mathrm{y}=2 \mathrm{x}-3)$. With the help of Random Number Generation (Microsoft Excel) we get the empirical error 10 -sequence $\left(\mathrm{u}_{1}\right.$, $\left.\mathrm{u}_{2}, \ldots, \mathrm{u}_{10}\right)$ as stochastic error $\mathrm{U} \sim \mathrm{N}(0,1)$ observed iid 10 -sequence. After that we fill up the column 2 $\mathrm{x}-3+\mathrm{u}$.

Table 2

For each value of regressor $x$ chosen we have measured the proper empirical value $\beta_{1} \cdot \mathbf{x}+\boldsymbol{\beta}_{0}+\mathbf{u}$ of random variable $\boldsymbol{\beta}_{1} \cdot \mathbf{x}+\boldsymbol{\beta}_{0}+\mathbf{U}$

\begin{tabular}{|c|c|c|c|}
\hline $\mathrm{x}$ & $\beta_{1} \cdot \mathrm{x}+\beta_{0}+\mathrm{u}$ & $\mathrm{y}=\beta_{1} \cdot \mathrm{x}+\beta_{0}$ & $\mathrm{u}$ \\
\hline $\mathrm{x}$ & $2 \mathrm{x}-3+\mathrm{u}$ & $\mathrm{y}=2 \mathrm{x}-3$ & $\mathrm{u}$ \\
\hline 2 & 0.70 & 1 & -0.30 \\
\hline 3 & 1.72 & 3 & -1.28 \\
\hline 4 & 5.24 & 5 & 0.24 \\
\hline 2 & 2.28 & 1 & 1.28 \\
\hline 4 & 6.20 & 5 & 1.20 \\
\hline 5 & 8.73 & 7 & 1.73 \\
\hline 3 & 0.82 & 3 & -2.18 \\
\hline 5 & 6.77 & 7 & -0.23 \\
\hline 4 & 6.10 & 5 & 1.10 \\
\hline 4 & 3.91 & 5 & -1.09 \\
\hline
\end{tabular}




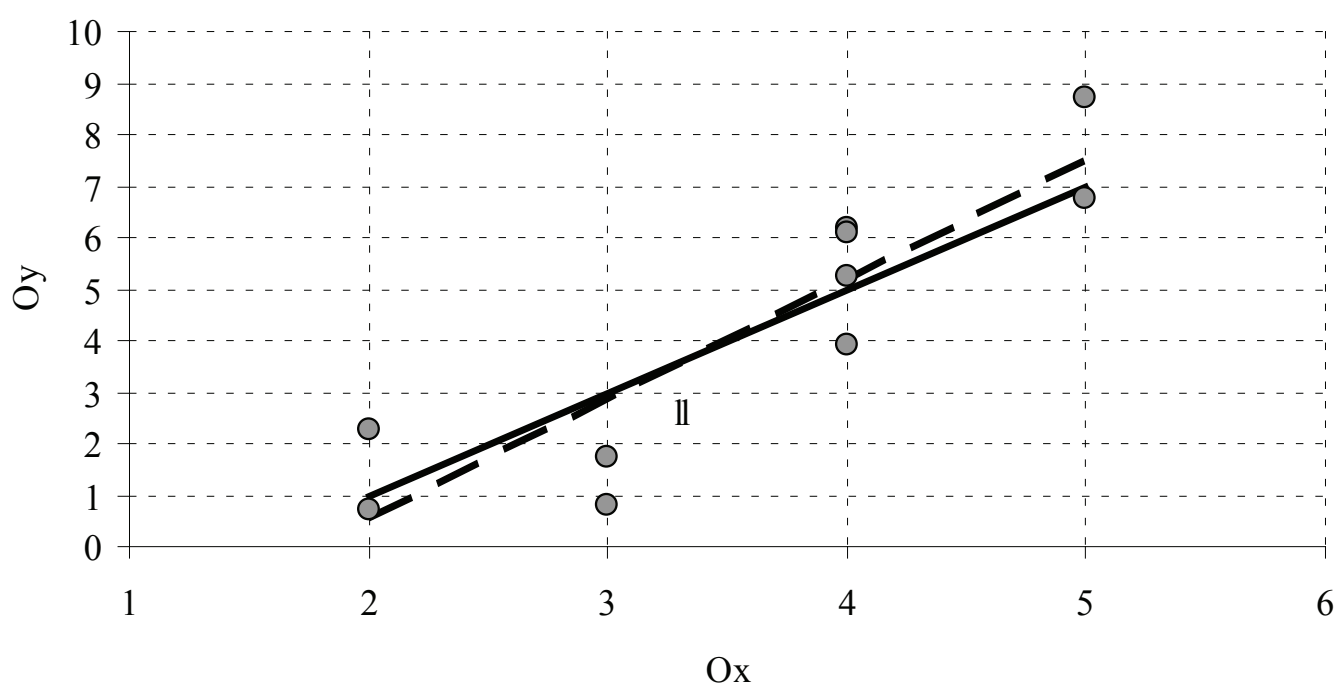

true dependance $\bigcirc$ observed points - - estimated dependance

Figure 3. The dependence $y=2 x-3$ exists objective, it is true dependence. With the help of statistic observations, we have 10 empirical points. The approximation of these 10 points by the least square method gives us the estimated equation $\mathrm{y}=2.31 \mathrm{x}-4.06$.

The econometrist disposes on a priori knowledge emphasized before, and empirical data shown in columns $x$ and $\beta_{1} \cdot x+\beta_{0}+u$.

Regressing $\beta_{1} \cdot x+\beta_{0}+u$ against $x$ we get $y=2.31$ $\mathrm{x}-4.06$ (Figure 3 ).

Based on the assumptions (1), (2), (3) and on the fundamental theorems of inductive statistics (Jaunzems, 2003b), the procedure Regression (Microsoft Excel) calculates the set of indicators presented in Summary Output Report.

Theorem. It is given that $\mathrm{y}=\beta_{1} \cdot \mathrm{x}+\beta_{0}$ and assumptions (1), (2), (3) hold.

Then results of 10 empirical observations pair of numbers $\left(\mathrm{x}, \beta_{1} \cdot \mathrm{x}+\beta_{0}+\mathrm{u}\right)$ shown in Table 2 imply that:

- estimated linear dependency between $\mathrm{x}$ and $\mathrm{y}$ is $\mathrm{y}=2.31 \mathrm{x}-4.06$;

- connections $\beta_{1} \in[1.54 ; 3.07], \beta_{0} \in[-6.92$; -1.20 ] hold with $90 \%$ confidence level;

- the expected value of estimator of unknown standard deviation $\sigma$ is 1.32 .

The theorems of inductive statistics are perfect verities about random objects and allow us to make inductive step from present to future.

The difficulties arise if we are going to investigate real processes with the help of inductive statistics theory.

It is necessary to answer the following questions.

(1) How are the real life objects and relations between them connected with theoretical model objects and relations between them? For instance, what does the concept of probability in real situation mean? (Similarly, as you cannot get free lunch, you cannot get free probability either.)

(2) How to verify what premises of inductive statistics theorems hold?

2. John Maynard Keynes criticism concerning insufficient scientific level of the Jan Tinbergen's investigation results.

In 1939, John Maynard Keynes keenly criticized professor Jan Tinbergen, who applied linear regression model in order to investigate investment volume's factors without rigorous verifying premises of inductive statistics theorems. The criticism expressed by J. M. Keynes concerning methods and praxis of inductive statistics seems to us urgent nowadays in Latvia.

We steadily ask the econometrists of Latvia to go deep in the criticism of J. M. Keynes from paper (Keynes, 1939) "Professor Tinbergen's Method" cited below.

(A) The first chapter, which should deal with the difficult logical problems involved in applying to economic data methods, which have been worked out in connection with material of a very different character, is grievously disappointing. As far as it goes, it is helpful; but it occupies only four pages. In addition, it leaves unanswered many questions, which the economist is bound to ask before he can feel comfortable as to the conditions, which the economic material has to satisfy if the proposed method is to be properly applicable. ... I would urge 
that next instalment should be primary devoted to the logical problem, explaining fully and carefully the conditions, which the economic material must satisfy if the application of this method to it is to be fruitful. ... At any rate, prof. Tinbergen agrees that the main purpose of his method is to discover, in cases where the economist has correctly analysed beforehand the quantitative character of the causal relations, with what strength each of them operates. If we already know what the causes are, then (provided all other conditions given below are satisfied) prof. Tinbergen, given the statistical facts, claims to be able to attribute to the causes their proper quantitative importance. ... Am I right in thinking that the method of multiple correlation analysis essentially depends on the economist having furnished, not merely a list of the significant causes, which is correct as far as it goes, but complete list? (Keynes, 1939; 559-560).

(B) Prof. Tinbergen explains that, generally speaking, he assumes that the correlations under investigation are linear. I have not discovered any example of curvilinear correlation in this book, and he does not tell us what kind of evidence would led him to introduce it. ... Am I right in thinking that the uniqueness of his results depends on his knowing beforehand that the quantitative effect of any factor on the phenomenon under investigation is directly proportional to the factor's own magnitude. (Keynes, 1939; 563).

(C) I pass in conclusion to a different department of the argument. How far are these curves and equations meant to be no more than a piece of historical curve fitting and description, and how far do they make inductive claims with reference to the future as well as the past? (Keynes, 1939; 566).

(D) Thirty years ago, I used to be occupied in examining the slippery problem of passing from statistical description to inductive generalization in the case of simple correlation. For the main prima facie $^{3}$ objection to the application of the method of multiple correlation to complex economic problems lies in the apparent lack of any adequate degree of uniformity in the environment. (Keynes, 1939; 567).

(E) The book is full of intelligence, ingenuity and endeavour; and I leave it with sentiments of respect for the author. But it has been a nightmare to live with, and I fancy that other readers will find the same....It is a strange reflection that this book looks likely, as far as 1939 is concerned, to be the principal activity and raisson d'être ${ }^{4}$ of the Leage of Nations. (Keynes, 1939; 568).
Our assertion is that the critical appraisal of econometric application given by John Maynard Keynes in 1939 can be completely assigned to many research papers in economics and business published in Latvia by methods of inductive statistics. Very often it is senseless even to speak about stochastic experiment because the most important condition - ceteris paribus does not fulfil, namely, economic environment is not homogeneous enough.

As the result, the causal inference derived from Regression Report is not scientifically correct.

At the same time, the applications of inductive econometrics in agriculture are much more justified because of possibility to repeat the stochastic experiments many times in constant circumstances like in physics and mechanics. It gives possibility, by repeating the experiment, to test the estimated causation repeatedly, and in that way to ascertain its veri tability.

3. Randomness and probability.

Renowned researcher of economics history $P h . D$. Lars Pålsson Syll in the portal larspsyll.worldpress. com published the series of articles concerning applications of inductive statistics in different areas of science. Let us shortly mention some statements expressed in the article "Randomization, experiments and claims of causality in economics" (Syll, 2012).

"Randomness obviously is a fact of the real world. Probability, on the other hand, attaches to the world via intellectually constructed models, and a fortiori is only a fact of a probability-generating machine or a well-constructed experimental arrangement or "chance set-up". Just as there is no such a thing as "free lunch", there is no such a thing as "free probability". To be able to talk about probabilities at all, you have to specify a model."

Lars Pålsson Syll wrote that regression models are widely used by social scientists to make causal inferences; such models are now almost a routine way of demonstrating counterfactuals. However, under the circumstances, reliance on model outputs may be quite unjustified. In our days, serious arguments have been made from data. Beautiful, delicate theorems have been proved although the connection with data analysis often remains to be established. In addition, an enormous amount of fiction has been produced, masquerading as rigorous science.

4. Some econometrics model in economics and agriculture.

4.1. Z-score bankruptcy forecasting model.

\footnotetext{
3 prima facie - initial (in French)

4 raisson d'être - the sense of existing (in France) The Leaque of Nations was "empty balloon" and John Maynard Keynes understood that.
} 
As illustration of a very non-critical regression model application nowadays in Latvia, we can mention the calculations and conclusions carried out with the help of well-known Z-score bankruptcy forecasting model given by Edward I. Altman:

$\mathrm{Z}=1.2 \mathrm{~T}_{1}+1.4 \mathrm{~T}_{2}+1.2 \mathrm{~T}_{1}+3.3 \mathrm{~T}_{3}+0.6 \mathrm{~T}_{4}+$ $0.999 \mathrm{~T}_{5}$,

where $T_{1}, T_{2}, T_{3}, T_{4}, T_{5}$ are relations often utilized in the firm's financial analysis.

It seems unbelievable, but this model has been used nowadays in Latvia in order to forecast the level of probability for firm's bankruptcy.

If $Z>2.99$ the firm is located in the safe zone;

if $1.81<Z>2.99$ the firm is located in the grey zone;

if $\mathrm{Z}<1.81$ the firm is located in the distress zone.

How unforgivingly far from true scientific investigation are the authors and their article reviewers that assume for suitable application of the Z-score model, derived in the USA in 1968 and based only on 66 observations, as a miracle-tool in Latvia, 2014. They spit about other time, other country, other circumstances.

For inductive purposes it is almost impossible to apply correctly the regression models in macroeconomics because of ceteris paribus condition usually does not hold.

4.2. Scientific econometric researches in agriculture.

Sufficiently better is the situation in the field of scientific econometric researches in agriculture agro metrics. Similarly, like in biometrics doing some kind of statistical research in agriculture, it is possible to organize scientific stochastic experiments that correspond to the proper theoretical conditions, namely, to be sure that the most important condition - ceteris paribus fulfils, and the environment of phenomenon is homogeneous enough.

We can find many successful applications of theorems of inductive statistics as a tool in decision analysis in agriculture, for example, in papers by $\mathrm{J}$. B. Hardaker, G. Lien, J. R. Anderson, and R. B. M. Huirne (Hardaker et al., 2015). The book "Coping with risk in agriculture: applied decision analysis / J. B. Hardaker, G. Lien, J. R. Anderson, and R. B. M. Huirne" contains a lot of references on successful investigation in agro metrics.

We have also much more closer examples. For instance, some successful investigation in agriculture provided with the help of inductive statistics was reported in the Section of Engineering during 15th International Scientific Conference "Engineering for Rural Development" provided by the Faculty of Engineering of Latvia University of Agriculture, and Latvia Academy of Agricultural and Forest Sciences.
In our opinion, the effect of management practices on time spent by cows in waiting area was suitably investigated, and in paper rather valid deductive conclusions (Gaworski \& Rocha, 2016) with the help of mathematical model based on inductive approach were obtained.

5. The response of modelers.

How do econometricians defend their causal inference made by insufficiently scientific methods?

Very interesting investigation provided by David A. Freedman reflects the typical response of modelers. D. A. Friedman asserts that the typical defences are the following (Friedman, 2005).

We know all that. Nothing is perfect. Linearity has to be a good first approximation. The assumptions don't matter. The assumptions are conservative. You can't prove the assumptions are wrong. We are only doing what everybody else does. If we don't do it, someone else will. What would you do? The models are not totally useless. You have to do the best you can with the data. You have to make assumptions in order to make progress.

These answers characterize the behaviour of scientists and are similar everywhere - in Western countries and in Latvia.

\section{Conclusions}

1. The critical appraisal of econometric application given by John Maynard Keynes in 1939 can be completely assigned to almost all published research in economics and business by methods of inductive statistics in Latvia. Very often it is senseless even to speak about stochastic experiment because the most important condition - ceteris paribus does not fulfil, namely, economic environment is not homogeneous enough. As the result, the causal inferences derived from Regression Report are not scientifically justified.

2. The calculations and interpretations of indicators in Regression Report (regressions, confidence intervals, t-statistics, p-values, etc.) are based on the theorems of inductive statistics. Therefore, the correct applications of these indicators for causal inference in economic or agricultural investigations require a priori knowledge and fulfilment of proper conditions. However, we must point out that scientists in Latvia as a rule openly ignore that applications of linear regression model endangers serious correctness and scientific ethics problems.

3. The applications of inductive econometrics in agriculture are much more justified because of possibility to repeat the stochastic experiments 
many times in constant circumstances like in physics and mechanics. It gives a possibility, by repeating the experiment, to test the estimated causation repeatedly, and in that way to ascertain its veritability.

4. We are sure that objective well-wishing criticism in econometrics applications area in order to keep the satisfactory level of scientific correctness and to avoid "the enormous amount of fiction produced, masquerading as rigorous science" has to be established in Latvia. It would be welcomed to find consensus between scientists to take critical notes in account only as scientific polemics.

\section{References}

1. Freedman, D. A. (2005). Limits of Econometrics. International Econometric Review. Retrieved October 12, 2016 from http://www.era.org.tr/ makaleler/99.pdf.

2. Gaworski, M., \& Rocha, A. G. F. (2016). Effect of management practices on time spent by cows in waiting area before milking. In: Engineering for Rural Development: 15th international scientific conference proceedings, Jelgava. Volume 15, pp. 1300-1304.

3. Hardaker, J. B., Lien, G., Anderson, J. R., \& Huirne, R. B. (2015). Coping with Risk in Agriculture: Applied Decision Analysis. CABI. $276 \mathrm{p}$.

4. Hoover, K. D. (2005). The Methodology of Econometrics. Article in Palgrave Handbooks of Econometrics, Volume 1: Theoretical Econometrics.

5. Jaunzems, A. (2003a). Matemātika. Kursa materiāli. Trešais izdevums. (Mathematics. Course materials. Third edition). Ventspils Augstskola. (in Latvian) 242 p.
6. Jaunzems, A. (2003b). Statistika. Ekonometrija. Kursu materiāli. Trešais izdevums. (Statistics. Econometrics. Course materials. Third edition). Ventspils Augstskola. (in Latvian) 231 p.

7. Jaunzems, A. (2015). Džona Meinarda Keinsa kritika Jana Tinbergena pētījumiem šodienas skatījumā (John Maynard Keyne's objections to the Jan Tinbergen's research from the nowadays view). Sabiedrība un kultūra. Rakstu krājums, XVII / Sastād. Arturs Medveckis. Liepāja: LiePA, pp. 226-235 (in Latvian).

8. Keynes, J. M. (1939). Professor Tinbergen's Method. The Economic Journal, 49 (195), pp. 558-568.

9. Keynes, J. M. (1940). Comment. The Economic Journal, 50 (197), pp. 154-156.

10. Syll, L. P. (2012, April). Randomization, experiments and claims of causality in economics. Theory of Science and Methodology. Retrieved September 10, 2016 from https://larspsyll. wordpress.com/2012/04/28/randomizationexperiments-and-claims-of-causality-ineconomics/.

11. Syll, L. P. (2013). Capturing causality in economics and the limits of statistical inference. real-world economics review, issue no. 64. Retrieved October 12, 2016 from http://www. paecon.net/PAEReview/issue64/Syll64.pdf.

12. Tinbergen, J. (1940). On a Method of Statistical Business-Cycle Research: A Reply. The Economic Journal, 50 (197), pp.141-154.

13. Кейнс, Д. М. (2007). Общая теория занятости, процента и денег. Избранное. (The General Theory of Employment, Interest and Money, 1936. The Selected Works). Москва: Эксмо. $960 \mathrm{c}$.

\section{Acknowledgements}

This research was done in the framework of the Nordplus Higher Education 2016 project NPHE-2016/10342 "Raising awareness about the role of math skills in building specialists competence for the sustainable development of society”. 